\title{
The Cooperative Effect of BSA Langmuir Monolayers and Magnesium Ions on Calcium Carbonate Crystallization
}

\author{
Zhonghui Xue ${ }^{1 *}$, Ning Xue ${ }^{2}$ \\ ${ }^{1}$ Shanghai Publishing and Printing College, Shanghai, China \\ ${ }^{2}$ Northeastern University, Qinhuangdao, China \\ Email: *hnlgxzh@163.com
}

How to cite this paper: Xue, Z.H. and Xue, N. (2019) The Cooperative Effect of BSA Langmuir Monolayers and Magnesium Ions on Calcium Carbonate Crystallization. Open Access Library Journal, 6: e5551. https://doi.org/10.4236/oalib.1105551

Received: June 18, 2019

Accepted: July 16, 2019

Published: July 19, 2019

Copyright $\odot 2019$ by author(s) and Open Access Library Inc.

This work is licensed under the Creative Commons Attribution International License (CC BY 4.0).

http://creativecommons.org/licenses/by/4.0/

(c) () Open Access

\begin{abstract}
The crystallization of calcium carbonate at interface of Langmuir monolayers of bovine serum albumin and subphase containing magnesium ions was studied in this paper. The results were characterized by using powder X-ray diffraction (XRD) and scanning electron microscopy (SEM). The effect rules were obtained by the cooperation of bovine serum albumin Langmuir monolayers and magnesium ions. BSA Langmuir monolayers controlled calcium carbonate to magnesium ions in solution. The experiment results showed that in the presence of both BSA Langmuir monolayers at interface and magnesium ions in solutions, an orientation aragonite with regular spherical morphology was precipitated. It is indicated that BSA Langmuir monolayers and magnesium ions have a cooperative effect on controlling the polymorph and orientation of calcium carbonate crystal. The experiments suggested that BSA Langmuir monolayer acts in combination with magnesium ions to inhibit calcite crystal growth, while favoring the formation of aragonite crystals.
\end{abstract}

\section{Subject Areas}

Nanometer Materials

\section{Keywords}

Calcium Carbonate, Bovine Serum Albumin, Langmuir Monolayer, Magnesium Ion, Biomineralization

\section{Introduction}

Many studies have been carried out on the mechanisms involved in biomineralization processes and several new biologically inspired synthetic routes have been designed for control of the formation of the mineral phase. One of the most 
intensely examined systems is calcium carbonate, which is abundant in biominerals, but also of industrial importance due to its wide use as a filler in paints, plastics, rubber, or paper. It has been shown that the polymorphism, morphology and structural properties of calcium carbonate can be controlled by the use of specific organic templates and/or additives. Langmuir monolayers [1] [2], ultrathin organic films [3], self-assembled films [4], have been used as effective templates for the controlled growth of calcium carbonate crystals, focusing on the control of the polymorph and crystal orientation. Cross-linked gelatin films [5], polymer substrates [6], and crystal-imprinted polymer surfaces [7] have also recently been used to direct the controlled growth of calcium carbonate crystals. Calcium carbonate films have been successfully prepared in the presence of both organic substrates and soluble polymeric additives [8] [9]. Interestingly, a designed peptide has been synthesized and used for the conformation-dependent control of the calcite morphology [10].

Proteins isolated from mollusk shells [11] [12] and intra-crystalline macromolecules from sea urchin spines [13] have shown distinct control on the polymorph of calcium carbonate crystals. The modulation of BSA on crystal morphology of calcium carbonate has been studied in vitro [14]. Manoli induced calcium carbonate crystals by chitin and elastin and obtained calcite crystals in both cases [15] [16]. Investigations show that proteins can modulate calcium carbonate morphology and also the polymorph [17] [18] [19]. Magnesium is known to exert a significant effect on calcium carbonate precipitation and, when present in sufficient concentration, generally results in the precipitation of aragonite rather than the thermodynamically favoured phase, calcite [20] [21] [22] [23] [24]. Recently, many groups have studied the role of magnesium in calcium carbonate precipitation. Meldrum studied the role of magnesium in stabilizing amorphous calcium carbonate and controlling calcium carbonate morphologies [25]. Dawe studied the influence of magnesium on the kinetics of calcite precipitation and calcite crystal morphology [26]. Further, protein as an organic matrix also plays a critical role in the biomineralization of the $\mathrm{CaCO}_{3}$ [2] [17], it exists at inorganic-organic interface of almost all the biominerals such as teeth, bones, pearls, mollusk shells [2] [18]. Many studies on the combined effect of organic additives and magnesium ions on calcium carbonate crystal growth have been reported recently [27] [28] [29], but the nucleation and growth of $\mathrm{CaCO}_{3}$ crystal in the $\mathrm{Mg}$ ions/Langmuir monolayers mixed system are not reported by now. This paper mainly discusses the cooperative influence of BSA Langmuir monolayer and magnesium ions on calcium carbonate precipitation. The aim of these experiments is to find the effect on the polymorph, morphology and orientation of calcium carbonate by combined BSA Langmuir monolayer and magnesium ions.

\section{Experimental Procedure}

\subsection{Materials}

Analytical grade $\mathrm{CaCO}_{3}$ and $\mathrm{MgCl}_{2} \cdot 6 \mathrm{H}_{2} \mathrm{O}$ were obtained from Institute of Bio- 
logical Products of Tianjin (Tianjin, China). Analytical grade bovine serum albumin (Sigma, USA) was used in all experiments. BSA contains 582 amino acid residues and has a molecular weight of $67,000 \mathrm{~g} \cdot \mathrm{mol}^{-1}$. It is also well known that it has an isoelectric point at $\mathrm{pI}$ 4.7. Amyl alcohol was analytical purity obtained from the (Sigma, USA). All solutions were prepared with triply deionized water, its conductivity was a resistance of $18.2 \mathrm{M} \Omega \cdot \mathrm{cm}^{-1}$ and its $\mathrm{pH}$ was 7.0.

The preparations of the protein Langmuir monolayers were performed using a commercial LB trough (KSV mini-trough, Finland) at room temperature. The pressure-area isotherms were recorded using a computer-controlled Langmuir film balance. The experimental errors for both molecular area and surface pressure values are smaller than $5 \%$. The monolayers deposition process at the air-solution interface were carried out using a microsyringe. The protein solutions were prepared with the deionized water, but to improve the spreading process a $0.05 \%(\mathrm{v} / \mathrm{v})$ solution of amyl alcohol was added in all cases [30] [31].

Supersaturated solutions of calcium bicarbonate were prepared according to the procedures of Kitana [32]. Briefly, carbon dioxide gas was bubbled through a stirred aqueous suspension of $\mathrm{CaCO}_{3}$ for 24 hours. The suspension was then filtered and filtrate purged with $\mathrm{CO}_{2}$ gas for 0.5 hours to dissolve any remaining crystals. The resulting supersaturated solution had a $\mathrm{pH}$ of 7.0. Total $\mathrm{Ca}^{2+}$ concentrations $(6.7 \mathrm{mM})$ were measured using EDTA titration. The spreading monolayers at the air-water interface were formed by spreading solutions of BSA $\left(1 \times 10^{-4} \mathrm{~mol} \cdot \mathrm{L}^{-1}\right)$ on the Supersaturated calcium bicarbonate solutions or supersatureated solution containing Mg ions. A 30-min lapse time was estimated to be sufficient to equilibrate the protein Langmuir monolayers before compression. We used very low compression rates, ca. $3 \mathrm{~mm} / \mathrm{min}$, which have been shown to be appropriate to obtain reproducible BSA isotherms [33].

\subsection{Method of Synthesizing Crystals}

In all experiments, crystallization was governed by the slow loss of $\mathrm{CO}_{2}$ gas from unstirred supersaturated solutions according to the reaction shown in Equation (1).

$$
\mathrm{Ca}^{2+}(\mathrm{aq})+2 \mathrm{HCO}_{3}^{-}(\mathrm{aq})=\mathrm{CaCO}_{3}(\mathrm{~s})+\mathrm{CO}_{2}(\mathrm{~g})+\mathrm{H}_{2} \mathrm{O}
$$

The crystals were grown by spreading BSA solution onto LB trough containing magnesium and supersaturated calcium bicarbonate solutions at room temperature. The solutions were combined in a beaker and were stirred for $2 \mathrm{~min}$ before pouring into the LB trough. The prepared supersaturated calcium bicarbonate solutions were poured into a Langmuir trough (KSV mini-trough), model $611 \mathrm{M}$; maximum working area, $220 \mathrm{~cm}^{2}$ ), and the air-water interface was swept and aspirated before deposition of the surfactant solution. The surfactant solution $(10 \mu \mathrm{L})$ was carefully deposited onto the solution surface, and the monolayers were left for $30 \mathrm{~min}$ prior to compression. Pressure-area isotherms were recorded while compressing the monolayers at rates of $3 \mathrm{~mm} \cdot \mathrm{min}^{-1}$ until surface pressures corresponding to a target pressure were reached $\left(15 \mathrm{mN} \cdot \mathrm{m}^{-1}\right)$. Each 
experiment was repeated three times with the same condition. Crystals as-grown in association with the monolayers were respectively removed at two conditions with keeping the same time (1 hour) by carefully horizontally dipping hydrophilic glass slides through the air-water interface. The crystal face growing into the solution is therefore directly deposited on the glass slide.

\section{Results and Discussion}

\subsection{The Influence of BSA Langmuir Monolayer and Magnesium on Polymorph and Orientation of $\mathrm{CaCO}_{3}$}

Figure 1(a) and Figure 1(b) show that XRD patterns of the resulting calcium carbonate in presence of BSA Langmuir monolayers without and with magnesium ions respectively. Figure 1(a) shows the XRD pattern of calcium carbonate in the presence of BSA Langmuir monolayers without magnesium ions, indicating that only one peak, which can be well attributed to (104) crystal planes diffraction of calcite (JCPDS 86-2342), which exhibits the crystals have a well orientation. When adding magnesium ions into the subphase beneath BSA Langmuir monolayer, only orientated aragonite crystals are precipitated (Figure 1(b)), corresponding to (111) crystal planes diffraction of aragonite (JCPDS 76-0606), which is in agreement with conventional theoretical results. Magnesium is known to induce aragonite formation from sea water and in vitro at ratio of $\mathrm{Mg} / \mathrm{Ca}$ equal to or greater than 4 , while at lower $\mathrm{Mg} / \mathrm{Ca}$ ratio mostly calcite and magnesian calcite are formed [32]. When BSA Langmuir monolayers are present alone the growth of $\mathrm{CaCO}_{3}$ crystals is greatly controlled, but there is no obvious change in $\mathrm{CaCO}_{3}$ polymorph and only calcite crystals are formed [14]. The above results show that when BSA Langmuir monolayers and magnesium are both present, only orientated aragonite crystals precipitated. This indicates that BSA Langmuir monolayers and magnesium ions have a cooperative effect on in controlling the orientation and polymorph of $\mathrm{CaCO}_{3}$ crystals. The reason of this kinetic phenomenon is considered as contributing to two aspects: on the

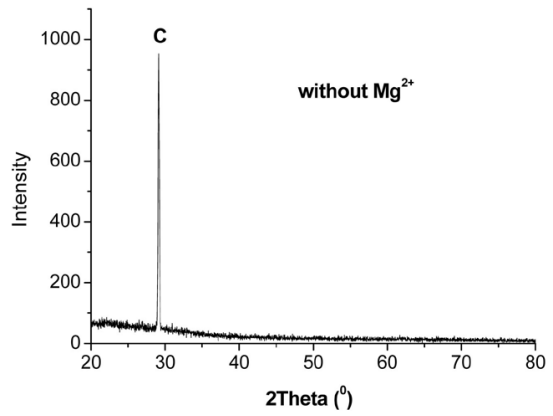

(a)

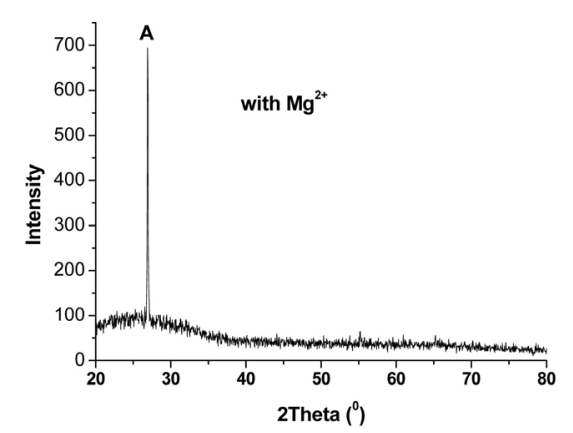

(b)

Figure 1. XRD data for calcium carbonate crystals modulated by BSA Langmuir monolayers and magnesium ions (C: calcite, $A$ : aragonite surface pressure $\Pi=15$, calcium ion is $6.7 \mathrm{mM}$ ). (a) Calcite crystals in the presence of BSA Langmuir monolayers and without magnesium ions (b) Aragonite crystals at $\mathrm{Mg} / \mathrm{Ca}=4$ in presence of BSA Langmuir monolaeyrs and with magnesium ions. 
one hand, magnesium ions inhibit the growth of calcite. The partially dehydrated magnesium ions attach to the surface of the nascent calcite nucleus, the strongly bound residual hydration sphere poisons the surface [33], and inhibits subsequent growth. At the same time, the BSA Langmuir monolayer acts as a template to control calcium carbonate oriented nucleation. On the other hand, owing to the polymorph of calcium carbonate is related to its energy state [34], magnesium is likely also to interact with BSA and to change the stereochemical structure of BSA molecules, and thus induces the aragonite with higher energy in high energy state structure.

\subsection{The Influence of the BSA Langmuir Monolayers and Magnesium on Morphology of $\mathrm{CaCO}_{3}$}

Two types of calcium carbonate morphologies are generated in the presence of BSA Langmuir monolayers and magnesium ions. In presence of BSA Langmuir monolayers, the crystals grow in absence of magnesium are regular almond-like calcite with an average length of $4.5 \mu \mathrm{m}$ and width of $2.5 \mu \mathrm{m}$ (Figure 2(a)). When the concentration of magnesium is high enough $(\mathrm{Mg} / \mathrm{Ca}$ ratio attains to 4), only spherical aragonite crystals are precipitated, about $1.5 \mu \mathrm{m}$ in size (Figure 2(b)).

Above results showed that only in the presence of BSA Langmuir monolayers regular almond-like calcite can be obtained. When magnesium is added, the morphology of crystals changed greatly, from almond-like to spherical. However, whether having magnesium or no, the crystals keep high orientation. The morphological changes of calcium carbonate crystals reveal that in the presence of both BSA Langmuir monolayers and magnesium ions, we tend to obtain spherical aragonite spherulites instead of other forms. Through controlling the concentration of magnesium in presence of BSA Langmuir monolayers, spherical crystals with more regular shapes and orientation could be obtained.

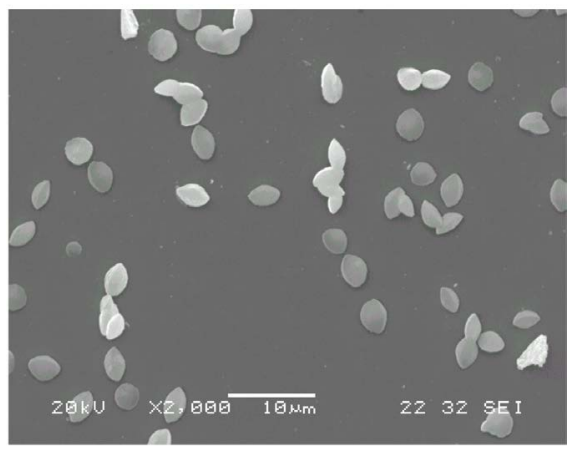

(a)

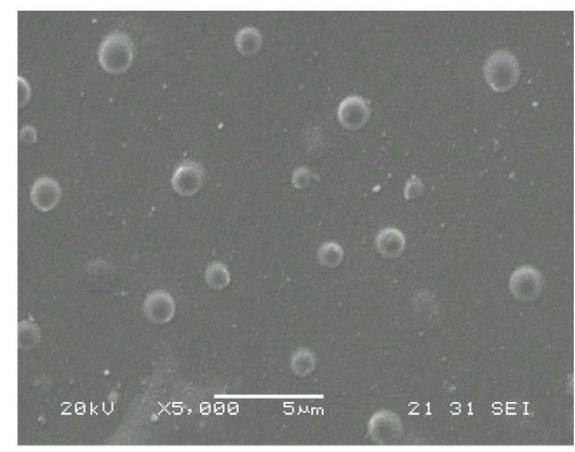

(b)

Figure 2. SEM morphologies of the calcium carbonate crystals precipitated in the presence of BSA Langmuir monolayers with and without magnesium ion (a) almond-like calcite crystal grown in the presence of BSA Langmuir monolayers without magnesium; (b) Spherical aragonite crystals at higher magnesium concentration in presence of BSA Langmuir monolayers. 


\section{Conclusions}

The present paper mainly studied the cooperative effect of BSA Langmuir monolayer and magnesium ions on calcium carbonate crystallization. The results indicated that BSA Langmuir monolayer has a promotional effect on magnesium ions in controlling the polymorph of $\mathrm{CaCO}_{3}$ crystals. By cooperation of BSA Langmuir monolayer and magnesium ions of different concentrations, crystals showed a sequence of morphology changes and especially, aragonite crystals with regular spherical morphology were precipitated at high $\mathrm{Mg} / \mathrm{Ca}$ ion concentration ratio. The experiments suggested that BSA Langmuir monolayer acts in combination with magnesium ions to inhibit calcite crystal growth, while favoring the formation of aragonite crystals.

In summary, the aragonite blocks could nucleate beneath the BSA Langmuir monolayers and magnesium ions with a well preferential orientation. There is a cooperative interaction between BSA Langmuir monolayers and magnesium ions, and these results are very significant for the understanding of the mechanism of biomineralization in the organic life. Further investigations are in progress.

\section{Acknowledgements}

This work was supported by the National Science Foundation of China, Grant No. 21203055 and Start-up funds for high-level introduction of talents for scientific research in Shanghai Publishing and Printing College.

\section{Conflicts of Interest}

The authors declare no conflicts of interest regarding the publication of this paper.

\section{References}

[1] Ahn, D.J., Berman, A. and Charych, D. (1996) Probing the Dynamics of Template-Directed Calcite Crystallization with in Situ FTIR. The Journal of Physical Chemistry, 100, 12455-12461. https://doi.org/10.1021/jp953536t

[2] Litvin, A.L., Valiyaveettil, S., Kaplan, D.L. and Mann, S. (1997) Template-Directed Synthesis of Aragonite under Supramolecular Hydrogen-Bonded Langmuir Monolayers. Advanced Materials, 9, 124-127. https://doi.org/10.1002/adma.19970090205

[3] Archibald, D.D., Qadri, S.B. and Gaber, B.P. (1996) Modified Calcite Deposition Due to Ultrathin Organic Films on Silicon Substrates. Langmuir, 12, 538-546. https://doi.org/10.1021/la950330a

[4] Aizenberg, J., Black, A.J. and Whitesides, G.M. (1999) Control of Crystal Nucleation by Patterned Self-Assembled Monolayers. Nature, 398, 495-498. https://doi.org/10.1038/19047

[5] Falini, G., Fermani, S., Gazzano, M. and Ripamonti, A. (1998) Oriented Crystallization of Vaterite in Collagenous Matrices. Chemistry: A European Journal, 4, 1048-1052.

https://doi.org/10.1002/(SICI)1521-3765(19980615)4:6<1048::AID-CHEM1048>3.0. 
$\underline{\mathrm{CO} ; 2-\mathrm{U}}$

[6] Dalas, E., Klepetsanis, P. and Koutsoukos, P.G. (1999) The Overgrowth of Calcium Carbonate on Poly(vinyl chloride-co-vinyl acetate-co-maleic acid). Langmuir, 15, 8322-8327. https://doi.org/10.1021/la981366g

[7] D’souza, S.M., Alexander, C., Whitcombe, M.J. and Vulfson, E.N. (1999) Directed Nucleation of Calcite at a Crystal-Imprinted Polymer Surface. Nature, 398, 312-316. https://doi.org/10.1038/18636

[8] Xu, G., Yao, N., Aksay, I.A. and Groves, J.T. (1998) Biomimetic Synthesis of Macroscopic-Scale Calcium Carbonate Thin Films. Evidence for a Multistep Assembly Process. Journal of the American Chemical Society, 120, 11977-11985. https://doi.org/10.1021/ja9819108

[9] Zhang, S. and Gonsalves, K.E. (1998) Influence of the Chitosan Surface Profile on the Nucleation and Growth of Calcium Carbonate Films. Langmuir, 14, 6761-6766. https://doi.org/10.1021/la970962s

[10] De Oliveira, D.B. and Laursen, R.A. (1997) Control of Calcite Crystal Morphology by a Peptide Designed to Bind to a Specific Surface. Journal of the American Chemical Society, 119, 10627-10631. https://doi.org/10.1021/ja972270w

[11] Falini, G., Albeck, S., Weiner, S. and Addadi, L. (1996) Control of Aragonite or Calcite Polymorphism by Mollusk Shell Macromolecules. Science, 271, 67-69.

[12] Levi, Y., Albeck, S., Brack, A. and Weiner, L.S. (1998) Control over Aragonite Crystal Nucleation and Growth: An in Vitro Study of Biomineralization. Chemistry: A European Journal, 4, 389-396.

https://doi.org/10.1002/(SICI)1521-3765(19980310)4:3<389::AID-CHEM389>3.0.C $\mathrm{O} ; 2-\mathrm{X}$

[13] Jain, G., Pendola, M., Rao, A., Cölfen, H. and Evans, J.S. (2016) A Model Sea Urchin Spicule Matrix Protein Self-Associates to Form Mineral-Modifying Protein Hydrogels. Biochemistry, 55, 4410-4421. https://doi.org/10.1021/acs.biochem.6b00619

[14] Shen, F.H., Feng, Q.L. and Wang, C.M. (2002) The Modulation of Collagen on Crystal Morphology of Calcium Carbonate. Journal of Crystal Growth, 242, 239-244. https://doi.org/10.1016/S0022-0248(02)01376-3

[15] Manoli, F. and Dalas, E. (1999) Mass Transfer in AlN Crystal Growth at High Temperatures. Journal of Crystal Growth, 201, 369-378. https://doi.org/10.1016/S0022-0248(99)00175-X

[16] Manoli, F., Koutsopoulos, S. and Dalas, E. (1997) Crystallization of Calcite on Chitin. Journal of Crystal Growth, 182, 116-124. https://doi.org/10.1016/S0022-0248(97)00318-7

[17] Kato, T., Suzuki, T., Amamiya, T. and Komiyama, N. (1998) Effects of Macromolecules on the Crystallization of $\mathrm{CaCO}_{3}$ the Formation of Organic/Inorganic Composites. Supramolecular Science, 5, 411-415. https://doi.org/10.1016/S0968-5677(98)00041-8

[18] Kato, T., Takuo, S. and Taku, I. (2000) Layered Thin-Film Composite Consisting of Polymers and Calcium Carbonate: A Novel Organic/Inorganic Material with an Organized Structure. Chemistry Letters, 29, 186-187. https://doi.org/10.1246/cl.2000.186

[19] Vucak, M., Peric, J., Pons, M.N. and Chanel, S. (1999) Morphological Development in Calcium Carbonate Precipitation by the Ethanolamine Process. Powder Technology, 101, 1-6. https://doi.org/10.1016/S0032-5910(98)00114-4

[20] Reddy, M.M. and Wang, K.K. (1980) Crystallization of Calcium Carbonate in the 
Presence of Metal Ions: I. Inhibition by Magnesium Ion at $\mathrm{pH} 8.8$ and $25{ }^{\circ} \mathrm{C}$. Journal of Crystal Growth, 50, 470-480. https://doi.org/10.1016/0022-0248(80)90095-0

[21] Mucci, A. and Morse, J.W. (1983) The Incorporation of $\mathrm{Mg}^{2+}$ and $\mathrm{Sr}^{2+}$ into Calcite Overgrowths: Influences of Growth Rate and Solution Composition. Geochimica et Cosmochimica Acta, 47, 217-233. https://doi.org/10.1016/0016-7037(83)90135-7

[22] Falini, G., Gazzano, M. and Ripamonti, A. (1996) Magnesium Calcite Crystallizatin from Water-Alcohol Mixtures. Chemical Communications, No. 9, 1037-1038. https://doi.org/10.1039/CC9960001037

[23] Falini, G., Fermani, S., Gazzano, M. and Ripmonti, A. (1997) Biomimetic Crystallization of Calcium Carbonate Polymorphs by Means of Collagenous Matrices. Chemistry: A European Journal, 3, 1807-1814.

https://doi.org/10.1002/chem.19970031113

[24] Raz, S., Weiner, S. and Addadi, L. (2000) Formation of High-Magnesian Calcites via an Amorphous Precursor Phase: Possible Biological Implications. Advanced Materials, 12, 38-42.

https://doi.org/10.1002/(SICI)1521-4095(200001)12:1<38::AID-ADMA38>3.3.CO;2 $\underline{-9}$

[25] Wilson, R.M., Seshadri, R. and Meldrum, F.C. (2003) The Role of Magnesium in Stabilising Amorphous Calcium Carbonate and Controlling Calcite Morphologies. Journal of Crystal Growth, 254, 206-218. https://doi.org/10.1016/S0022-0248(03)01153-9

[26] Zhang, Y. and Dawe, R.A. (2000) Influence of $\mathrm{Mg}^{2+}$ on the Kinetics of Calcite Precipitation and Calcite Crystal Morphology. Chemical Geology, 163, 129-138. https://doi.org/10.1016/S0009-2541(99)00097-2

[27] Falini, G., Gazzano, M. and Ripamonti, A. (1994) Crystallization of Calcium Carbonate in Presence of Magnesium and Polyelectrolytesf. Journal of Crystal Growth, 137, 577-584. https://doi.org/10.1016/0022-0248(94)91001-4

[28] Sugawara, A. and Kato, T. (2000) Aragonite $\mathrm{CaCO}_{3}$ Thin-Film Formation by Cooperation of $\mathrm{Mg}^{2+}$ and Organic Polymer Matrices. Chemical Communications, No. 6, 487-488. https://doi.org/10.1039/a909566g

[29] Meldruma, F.C. and Hyde, S.T. (2001) Morphological Influence of Magnesium and Organic Additives on the Precipitation of Calcite. Journal of Crystal Growth, 231, 544-558. https://doi.org/10.1016/S0022-0248(01)01519-6

[30] Pins, G.D., Chirstiansen, D.L., Patel, R. and Silver, F.H. (1997) Self-Assembly of Collagen Fibers. Influence of Fibrillar Alignment and Decorin on Mechanical Properties. Biophysical Journal, 73, 2164-2172. https://doi.org/10.1016/S0006-3495(97)78247-X

[31] Aizenberg, J., Hanson, J., Weiner, S. and Addadi, L. (1997) Control of Macromolecule Distribution within Synthetic and Biogenic Single Calcite Crystals. Journal of the American Chemical Society, 119, 881-886. https://doi.org/10.1021/ja9628821

[32] Kitano, Y. (1962) The Behavior of Various Inorganic Ions in the Separation of Calcium Carbonate from a Bicarbonate Solution. Bulletin of the Chemical Society of Japan, 35, 1973-1980. https://doi.org/10.1246/bcsj.35.1973

[33] Noyes, R.M. (1962) Thermodynamics of Ion Hydration as a Measure of Effective Dielectric Properties of Water. Journal of the American Chemical Society, 84, 513-522. https://doi.org/10.1021/ja00863a002

[34] McCanley, J.W. and Roy, R. (1974) Controlled Nucleation and Crystal Growth of Various $\mathrm{CaCO}_{3}$ Phases by the Silica Gel Technique. American Mineralogist, 59, 947-963. 